\title{
VENTA DE ÓRGANOS Y DESIGUALDAD SOCIAL*
}

\author{
Ricardo García Manrique \\ Universidad de Barcelona \\ garcia.manrique@ub.edu
}

RESUMEN. La necesidad de disponer de más órganos humanos para trasplante ha llevado a proponer la legalización de su venta, con el fin de aumentar su oferta. Cuando lo que se propone es un mercado regulado que trata de evitar los efectos más injustos del comercio de órganos, parece haber una presunción a favor de su legitimidad. Contra esta presunción, cabe formular dos tipos de argumentos: los basados en la desigualdad social y los basados en la degradación del valor del cuerpo humano. Se analizan aquí los primeros y se concluye que no parecen suficientes para refutar la presunción. Por tanto, solo un argumento del segundo tipo podría justificar la prohibición de mercantilización de los órganos humanos.

Palabras clave: órganos humanos, mercado, desigualdad, bioética.

\section{Organ sales and social inequality}

ABSTRACT. The need to have more human organs for transplant has led to propose the legalization of organ sales, in order to increase their supply. When what is proposed is a regulated market that tries to avoid the most unfair effects of organ trade, there seems to be a presumption in favor of its legitimacy. Against this presumption, two types of arguments can be raised: those based on social inequality and those based on the degradation of the value of the human body. The first ones are analyzed here and we arrive at the conclusion that they do not seem enough to overcome the presumption. Therefore, only an argument of the second kind could justify the prohibition of commodification of human organs.

Keywords: human organs, markets, inequality, bioethics.

* Fecha de recepción: 4 de abril de 2019. Fecha de aceptación: 27 de junio de 2019.

Proyecto de Investigación «El Convenio de Oviedo cumple veinte años: propuestas para su adaptación a la nueva realidad social y científica» (MINECO DER2017-85174-P). Debo agradecer a un revisor anónimo sus muy atinadas observaciones, que me han ayudado a mejorar el texto. 


\section{1. ¿POR QUÉ NO UN MERCADO DE ÓRGANOS?}

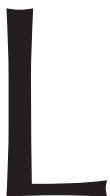

a compraventa de órganos humanos está prohibida por el derecho internacional y por la mayor parte de los sistemas jurídicos nacionales ${ }^{1}$. Sin embargo, desde hace ya tiempo se viene proponiendo su legalización, como un medio eficaz para paliar la escasez de órganos para trasplante ${ }^{2}$. Un ejemplo significativo es el de Gary BECKER, uno de los más reputados economistas de las últimas décadas y Premio Nobel en 1992, que en un artículo publicado en 2007 trató de justificar la capacidad de un mercado de riñones para aumentar la oferta y así reducir considerablemente las listas de espera. Gran parte del artículo se ocupaba del aspecto empírico de la cuestión, pero su argumento de fondo era de orden moral y aparecía en las últimas líneas:

La respuesta más efectiva a los críticos de la compraventa de órganos es que el sistema actual [el que prohíbe la compraventa] impone una carga intolerable en miles de individuos enfermos que sufren y a veces mueren mientras esperan años hasta que pueden disponer de un órgano compatible. El aumento de la oferta producido por el pago eliminaría su espera en buena medida ${ }^{3}$.

La de BECKER no es una propuesta aislada, ni tampoco es una propuesta descabellada. Para empezar, es evidente que faltan riñones y otros órganos para trasplante, y también lo es que, si dispusiéramos de un número mayor de órganos, la salud de muchas personas mejoraría y muchas vidas se salvarían. En cambio, no es tan evidente: a) que el establecimiento de un mercado de órganos aumente su oferta, acaso porque la mercantilización de los órganos humanos pueda implicar una reducción del número de donantes ${ }^{4}$, o porque no parece plausible creer que, en una sociedad avanzada en términos de riqueza e igualdad, la gente esté dispuesta a vender sus órganos ${ }^{5}$; b) que la otra fuente de obtención de órganos humanos (la extracción a partir de cadáveres) sea incapaz de satisfacer la demanda, siquiera sea porque es una fuente que todavía no ha sido aprovechada al máximo, tal como debería serlo ${ }^{6}$, y c) que la donación de órganos no conlleve riesgos significativos para la salud de los donantes ${ }^{7}$. Sin embargo, con el

${ }^{1}$ El art. 21 del Convenio de Oviedo (Convenio para la protección de los derechos humanos y la dignidad del ser humano con respecto a las aplicaciones de la Biología y la Medicina, de 1997) establece: «El cuerpo humano y sus partes, como tales, no deberán ser objeto de lucro». La Carta de los Derechos Fundamentales de la Unión Europea, de 2000, en su art. 3.2, establece que «en el marco de la medicina y la biología se respetarán en particular [...] la prohibición de que el cuerpo humano o partes del mismo en cuanto tales se conviertan en objeto de lucro». Cláusulas similares pueden encontrarse en casi todos los ordenamientos jurídicos nacionales, a salvo de alguna excepción como la de Irán. En 2015 se aprobó el Convenio de Santiago de Compostela, o Convenio del Consejo de Europa contra el tráfico de órganos humanos (sobre este Convenio, vid. PONS RAFOLS, 2016).

2 SATZ, 2010: 189.

3 BECKER y ELÍAS, 2007: 22. Una versión resumida de su propuesta se encuentra en BECKER y ELIÍAS, 2014.

4 Titmuss, 1973: 277; Garzón Valdés, 1994: 182; Rothman y Rothman, 2006: 1524-1526; SaTZ, 2010: 192

5 RIVERA LÓPEZ, 2001: 179.

${ }^{6}$ De LORA, 2011 y 2012. También cabría incentivar la donación de órganos en vida mediante compensaciones distintas del «precio» (ATIENZA, 2010: 129; PUYOL, 2019: 52-54, en relación con la donación de sangre; en general, sobre los incentivos o nudges como política pública a explorar, vid. SUNSTEIN, 2019). Sin embargo, supondré que la vía de la incentivación no basta para generar un aumento de oferta que satisfaga la demanda.

7 Buisan, García ManRiQue, Mautone y NaVARRo, 2011: 25-27. De hecho, estos autores proponen, por esa razón, que la obtención de órganos de donante vivo sea considerada una práctica muy restringida, y subsi- 
fin de evaluar la bondad de propuestas como la de BECKER y otras afines, voy a dar por bueno que es así, esto es: que la mercantilización de los órganos aumentaría su oferta, que los órganos procedentes de cadáver no resultan suficientes y que los daños para el donante son mínimos o, en todo caso, mucho menores que los beneficios para quienes reciben el trasplante.

Siendo así, parece haber una presunción a favor de la legalización del comercio de órganos, si resulta que esta legalización redundaría en una mejora importante de la salud de muchas personas o incluso en el salvamento de sus vidas. Tal como lo expresa Stephen WiLKINSON:

El argumento es sencillo. Permitir (o fomentar) la venta de órganos [...] salva vidas porque (al menos parcialmente) reduce la escasez de órganos para trasplante. Salvar vidas es un buen fin, y la venta de órganos es pues defendible como un medio para lograr ese fin ${ }^{8}$.

Ante un argumento como este, y para oponerse a él, uno puede cuestionar su base empírica (que la venta de órganos salvavidas), o bien puede aceptarla pero rechazar su consecuencia práctica (permitir la venta de órganos) sobre la base de otras razones. En todo caso, si se acepta la base empírica, WILKINSON sostiene que la carga de la prueba cae sobre los «prohibicionistas», dada la fuerza prima facie del argumento del salvamento de vidas. RADCLIFFE RICHARDS es de la misma opinión, dado que, a su juicio, los «daños» causados por la prohibición son claros: no solo el daño causado a quienes podrían salvar su vida o mejorar su salud comprando un órgano, sino también el daño causado a quienes querrían vender un órgano y no pueden hacerlo:

En una sorprendente contravención de nuestras ideas habituales sobre la libertad individual, impedimos que los adultos suscriban libremente contratos de los que ambas partes esperan beneficiarse, sin daño obvio para nadie más? .

Sin embargo, no estoy seguro de que esta restricción de nuestra capacidad contractual y de nuestra capacidad de disposición sobre partes de nuestro cuerpo haya de resultar «sorprendente» teniendo en cuenta nuestras «ideas habituales sobre la libertad individual», precisamente porque estas ideas también incluyen la conciencia de ciertas restricciones de esa libertad en relación con la disponibilidad del propio cuerpo y de sus partes y en relación con el ámbito de lo contratable, incluso cuando el daño para los demás no resulte «obvio» ${ }^{10}$. Tampoco resulta convincente un tercer fundamento sobre el que cabría asentar la presunción a favor de la legalización, el de la «consistencia» o coherencia con otras prácticas generalmente asumidas, como la de «vender» nuestro trabajo ${ }^{11}$. Primero, porque este fundamento acaso no sea más que una variante del anterior (que cabe llamar el del favor libertatis o el de la primacía de la autonomía

\footnotetext{
diaria respecto de la obtención de órganos de cadáver. En particular, señalan que en muchos casos el perjuicio causado a la salud del donante puede ser mayor que el beneficio para la salud del receptor, si, por ejemplo, la esperanza de vida de este es corta.

8 WILKINSON, 2015: 3 .

9 RADCLIFFE RICHARDS, 1996: 377.

${ }^{10}$ La pretensión libertaria de que tenemos un derecho de propiedad sobre nuestro cuerpo y sobre sus partes separadas (de la que derivaría a su vez el derecho a su venta) la considero inaceptable (GARCíA MANRIQUE, 2016 y 2018a). En todo caso, sería al revés: si nos inclinamos (con base en otras razones) por la legalización de la venta de partes separadas del cuerpo, tendríamos una razón digamos técnico-jurídica para someterlas al estatuto de la propiedad.

11 Savulescu, 2003: 138-139; Wilkinson, 2015: 3.
} 
individual); pero además, en contra de la opinión de SAVULESCU, porque parece haber una diferencia relevante, al menos en principio, entre vender nuestro trabajo y vender partes de nuestro cuerpo. Esta diferencia puede, desde luego, ponerse en cuestión, pero lo que no parece razonable es fundar una presunción sobre su supuesta inexistencia.

En todo caso, el argumento del salvamento de vidas me parece lo bastante fuerte como para que el planteamiento de WILKINSON (y parciamente al menos el de RADCLIFFE RICHARDS) resulten aceptables, esto es, que por esa razón existe una presunción a favor del comercio de órganos, sobre todo cuando no hay un valor, un principio o un derecho fundamental que pueda oponérsele de manera evidente ${ }^{12}$. Entre estos últimos, el candidato con más posibilidades acaso sería el derecho a la integridad física. Sin embargo, este derecho se ha configurado históricamente, y hasta la actualidad, como un derecho «negativo» $\mathrm{o}$ «reaccional» (una «inmunidad» más que una «libertad»), que protege la intangibilidad, pero no se ha desarrollado en relación con la libre disposición, de manera que la cuestión de si podemos o no podemos vender partes de nuestro cuerpo queda fuera de su ámbito ${ }^{13}$. Por eso, aunque el argumento del salvamento de vidas pueda ser calificado como consecuencialista ${ }^{14}$, el partidario de una ética deontológica bien puede asumirlo como propio, por lo menos hasta que consiga encontrar un argumento deontológico contrario de mayor peso. Por tanto, y como no cuestionaré la base empírica del argumento sino que la daré por supuesta, asumiré que la carga de la prueba recae en los prohibicionistas.

Cabría discutir, aunque no lo haré aquí, si ante una prohibición jurídica largamente arraigada como es la de la venta de órganos, la carga de la prueba no habría de recaer en quienes pretenden abolir la prohibición, esto es, alterar el orden jurídico establecido $^{15}$. Entiendo que WilKINSON, RADCLIFFE RichardS o SATZ no tienen en cuenta a estos efectos el «estado de cosas jurídico», sino simplemente los argumentos morales más inmediatamente disponibles a favor o en contra de la prohibición. Y porque se trata de argumentos y no de intuiciones (puesto que nos hallamos en el terreno del razonamiento práctico), creo que debe desestimarse la presunción a favor de la prohibición basada en la intuitiva repugnancia que genera el comercio de órganos ${ }^{16}$. En fin, una última razón que abona aquí y abora la presunción a favor de la legalización del comercio de órganos es que la muy personal intuición de quien esto escribe le inclina a oponerse a esa legalización y, en términos argumentativos, parece sensato partir de la posición contraria a la propia para ver si puede ser contradicha.

12 Debra SatZ, quien, a diferencia de WiLKINSON y RADCLIFFe RichaRDS, no es partidaria del comercio de órganos, asume también la misma presunción. SATZ, 2010: 189.

13 Pascual Medrano, 2018: 52-54 y 61; Escobar Roca, 2018a: 58 y ss. Otra cosa es que, tal como sostiene Amelia PASCUAL, el derecho a la integridad física esté aquejado de «fatiga funcional» precisamente por su incapacidad para «proporcionar a su titular un ámbito de garantía o autodeterminación bastante en orden a la disposición de elementos corporales y su posterior control» (PASCUAL MEDRANO, 2018: 66). En general, Guillermo ESCOBAR cree que los derechos a la vida y a la integridad física se quedan cortos a la hora de dar soluciones a los problemas bioéticos; y aboga por recurrir a la ponderación de los valores constitucionales de libertad y dignidad (ESCOBAR ROCA, 2018a y 2018b: 106).

${ }^{14}$ RIVERA LÓPEZ, 2001: 163.

15 Sobre la tradición jurídica de conservación de lo corporal fuera del ámbito de lo comercial, y sobre cómo está quebrando en los últimos tiempos, vid. MÉNDEZ BAIGES, 2018.

16 RADCLIFFE RICHARDS, 1996: 401. 
Teniendo en cuenta la presunción a favor del comercio de órganos y asumiendo pues la carga de la prueba de la conveniencia de su prohibición, ¿es posible articular un argumento sólido contra el comercio de órganos que vaya más allá de la intuición, la repugnancia, la tradición o la mera invocación del derecho positivo? Creo que sí o, por lo menos, creo que es razonable intentarlo. Con este fin: i) expondré una propuesta concreta y particularmente atractiva de legalización del comercio de órganos; ii) identificaré los argumentos que pueden esgrimirse contra ella, y iii) examinaré aquellos que se vinculan con la idea de que el comercio de órganos se aprovecha de la desigualdad social y económica y/o genera más desigualdad de ese tipo. Concluiré que estos argumentos no parecen suficientes para desvirtuar la presunción a favor del comercio de órganos y que, por tanto, quien lo pretenda deberá apoyarse en argumentos de otro tipo, en particular en aquellos que sugieren que el comercio de órganos contribuye a una indeseable degradación del valor de lo corporal. Su examen, confío en que más prometedor, habrá de quedar para otra ocasión.

\section{LA PROPUESTA DE ERIN Y HARRIS}

Charles ERIN y John HARRIS han propuesto un mercado regulado y «ético» de órganos humanos ${ }^{17}$. Su punto de partida es el que hemos dado por bueno: los trasplantes salvan vidas y mejoran la salud de muchos, hay escasez de órganos, y un mercado de órganos la reduciría ${ }^{18}$. Su propuesta es interesante porque establece con cierta precisión las condiciones en que sería legítimo, o éticamente aceptable, un mercado de órganos, y porque esas condiciones permiten descartar una buena parte de las objeciones morales dirigidas contra el comercio de órganos. Estas objeciones valen pues para algunos mercados, pero no para todos; por eso, si se trata de articular un argumento contra cualquier mercado de órganos, tomar la propuesta de ERIN y HARRIS como punto de referencia puede ser una buena idea ${ }^{19}$.

El mercado que proponen ERIN y HARRIS tendría las siguientes características:

i) Sería un «monopsonio» público, esto es, un mercado en el que solo hay un comprador, que es público (pensando en su país, los autores apuntan al National Health Service; para otros países, cualquier otra institución con funciones similares serviría).

ii) Sería un mercado circunscrito geopolíticamente al ámbito de un estado (o unión de estados, como la Unión Europea), de manera que solo los ciudadanos de esa unidad política podrían vender sus órganos, y solo los ciudadanos podrían recibir uno de esos órganos (rectius: solo los beneficiarios del sistema sanitario de ese estado, sean o no «ciudadanos» stricto sensu; pero seguiré hablando de «ciudadanos» para simplificar).

iii) El precio de compra sería único y fijado por el comprador. Debería ser «lo suficientemente alto para atraer a los vendedores», y hay que suponer que variaría

17 ERIN y HARRIS, 1994, 2002 y 2003.

18 ERIN y HARRIS, 2003: 137.

19 Por cierto, que la propuesta de ERIN y HARRIS ha sido criticada por demasiado restringida (RADCLIFFE RICHARDS, 2003: 140), pero esto lo dejaremos aquí de lado, precisamente porque de lo que se trata es de saber si incluso una propuesta tan restringida es aceptable. 
en función de la oferta y la demanda (los autores no son muy explícitos en este punto) ${ }^{20}$.

iv) La asignación o distribución de los órganos se realizaría al margen de criterios mercantiles y de acuerdo con «una concepción justa de la prioridad médica». Sin embargo, los vendedores de órganos tendrían prioridad a la hora de recibir un órgano, si más adelante lo necesitaran. Es decir, el comprador compra órganos, pero no los vende, sino que los asigna de acuerdo con una lógica que podemos llamar «ciudadana» ${ }^{21}$.

Además de presentar las asumidas ventajas de un mercado de órganos (en síntesis: salvar vidas y mejorar la salud), las ventajas adicionales de un mercado como este serían por lo menos las siguientes:

i) Se evitaría la explotación de los habitantes de los países pobres, puesto que solo los ciudadanos podrían vender sus órganos. De otra manera, aquellos serían explotados no solo porque acaso el acto mismo de la compra del órgano podría suponer un abuso de su hipotética situación de pobreza extrema, sino porque contribuirían al sistema de distribución (vendiendo sus órganos), pero no podrían beneficiarse de él (al no ser beneficiarios del sistema sanitario del país de referencia).

ii) Se evitaría (al menos en alguna medida) la explotación de los vendedores: en primer lugar, porque se evitarían las transacciones directas entre el vendedor y el destinatario último del órgano, que pueden pensarse generadoras de mayor explotación que si es la comunidad la que compra los órganos; en segundo lugar, porque cabe suponer (aunque los autores no lo dicen expresamente) que el precio sería mínimamente justo; en tercer lugar, porque los vendedores serían compensados no solo mediante el precio, sino además por la prioridad a la hora de recibir un órgano si lo necesitaran.

iii) Se evitaría beneficiar a los ciudadanos ricos en el reparto de los órganos, puesto que los órganos son asignados según criterios no mercantiles, sino de «justicia sanitaria». Es decir, la capacidad económica de aquel que necesita el órgano devendría irrelevante a la hora de conseguirlo.

iv) Se preservaría (en alguna medida) el valor intrínseco de los órganos, puesto que su uso estaría restringido a fines sanitarios y su distribución seguiría criterios de necesidad.

Un mercado de órganos (riñones) similar en algunos aspectos al propuesto por ERIN y HARRIS es el que está vigente en Irán desde 1988: es un mercado limitado a los ciudadanos, y el estado paga una parte del precio del riñón. Sin embargo, las transacciones son directas entre el vendedor y el receptor del órgano (aunque mediadas por una agencia sin ánimo de lucro) y este paga una parte variable del precio, a la que hay que sumar una parte fija pagada por el estado ${ }^{22}$. De cara a evaluar la bondad de la compraventa de órganos desde un punto de vista moral, no creo necesario tener en cuenta el modelo iraní, porque no parece aportar ventajas (morales) al modelo de ERIN y HARRIS y acaso sí alguna desventaja, como la que supone que el receptor del órgano haya de pagar al menos una parte de su precio.

20 Para hacernos una idea aproximada del precio de un órgano humano, podemos tomar en consideración la estimación de BECKER y ELÍAs: en un sistema de precio libre, un riñón costaría entre 5.000 y 25.000 dólares; pero buena parte de ellos estaría disponible en torno a 15.000 dólares (BECKER y ELÍAS, 2004: 3).

21 García ManRIQUe, 2018b.

22 MatesanZ, 2018; MAHDAVI-MaZdeH, 2012. 
Cécile FABRE también ha propuesto un mercado regulado de órganos ${ }^{23}$. Las diferencias con la propuesta de ERIN y HARRIS son: i) los órganos serían comprados por agencias no gubernamentales sin ánimo de lucro, a cambio de un precio fijado por el estado (lo que quiere evitar FABRE es que un mismo sujeto sea quien fije el precio y quien compre, para evitar que los precios tiendan a la baja y se perjudique indebidamente a los vendedores); ii) se insiste expresamente en que el precio fijado por el estado debería ser un precio justo, en el sentido de que evitase la explotación de vendedores y de compradores, y iii) las agencias venderían los órganos a los pacientes. Esta última es la diferencia más significativa, esto es, que los receptores pagarían un precio por el órgano; pero hay que tener en cuenta que la propuesta de FABRE se encuadra en un más amplio sistema de redistribución de órganos, que incluye su confiscación por razones de salud ${ }^{24}$. Lo que postula FABRE es el deber ciudadano de ceder órganos a quienes los necesitan para llevar una vida mínimamente decente (a minimally flourishing life), si esa cesión no conlleva un daño grave (por ejemplo: quien tuviera dos riñones habría de ceder uno a quien no tiene ninguno). Esto explica que, más allá del sistema confiscatorio, quienes quisieran comprar un órgano lo harían por razones no estrictamente sanitarias, sino, digamos, de «perfeccionamiento» (el ejemplo que pone FABRE es el de quien, teniendo un solo riñón, quiere ser atleta de élite, para lo que, según parece, se necesitan dos riñones); de aquí que se justifique el pago de un precio por el órgano, pues ese perfeccionamiento queda fuera de lo sometido a la justicia distributiva. La propuesta de FABRE es digna de consideración, pero no lo haré aquí porque desborda el objeto de este trabajo. A la hora de evaluar la bondad de un mercado de órganos, supondré que no se ha establecido un mecanismo confiscatorio y, por eso, no tendré en cuenta la propuesta de mercado de FABRE, cuyas especificaciones dependen de la previa existencia de ese mecanismo.

\section{LOS ARGUMENTOS CONTRA EL MERCADO DE ÓRGANOS}

Tenemos, pues, una presunción a favor de la legalización del comercio de órganos, si contribuye a salvar vidas, y tenemos también una propuesta de regulación de ese comercio que reduce en cierta medida los males que podrían derivarse de él. En estas condiciones, ¿qué argumentos podrían ofrecerse para desvirtuar esa presunción? Si nos fijamos en lo que suele decirse y escribirse al respecto, nos encontramos con la invocación de una larga serie de conceptos positivos y negativos: altruismo, consentimiento, dignidad, autonomía, libertad, integridad, daño, riesgo, coacción, abuso, explotación, desigualdad, cosificación, degradación, corrupción. A partir de aquí, cabría identificar un buen número de argumentos, pero creo posible reducirlos a dos o, acaso mejor, a dos grupos que permiten sendos tratamientos unitarios: i) argumentos basados en la desigualdad, y ii) argumentos basados en la degradación. Al margen de esta reducción queda el argumento basado en el daño (o riesgo de daño) que sufren quienes se desprenden de un órgano, pero aquí lo dejaré de lado porque asumí al

23 FABRE, 2006: 149-152.

24 Ibid., 98-125. Un modelo confiscatorio, pero de órganos de cadáver, lo defiende también Pablo DE LORA (DE LORA, 2011). En la misma línea, Pol CuAdros y Ângel PuYol han propuesto un deber cívico (jurídicamente vinculante) de donar sangre (CUADROS AGUILERA, 2017 y 2018: 241 y ss.; PUYOL, 2019: 54-56). 
principio que este daño es mucho menor que el beneficio causado a quienes reciben el órgano. Obsérvese, dicho sea de paso, que el argumento del daño vale tanto contra el comercio de órganos como contra su donación. Es decir, se trata de un argumento dirigido no específicamente contra el comercio sino contra el trasplante de órganos entre vivos, sea o no mediante precio. Por eso, ha sido utilizado para desalentar este tipo de trasplantes ${ }^{25}$.

Los argumentos basados en la desigualdad giran en torno a la idea de que el comercio de órganos se aprovecha de una desigualdad injusta o la genera. Los argumentos basados en la degradación (o corrupción) sostienen que el comercio de órganos impide valorar correctamente ciertos bienes sociales. Michael SANDEL, por ejemplo, lo resume así:

¿Pero es lícito comprar y vender riñones? Quienes dicen que no basan su objeción en dos motivos: argumentan que este mercado se aprovecha de los pobres, cuya decisión de vender un riñón puede no ser verdaderamente voluntaria (argumento de la justicia); o que este mercado fomenta un concepto degradante, cosificador, de la persona humana como conjunto de partes corporales de repuesto (argumento de la corrupción) ${ }^{26}$.

También Cécile FABRE, Elizabeth WiCKS o María CASADO recurren a un esquema equivalente. A juicio de las dos primeras, las objeciones relevantes contra la venta de órganos son dos: la objeción de la mercantilización (commodification) y la objeción de la explotación; a juicio de la tercera, las objeciones se basan en el valor de la justicia (y de la solidaridad) y en el hecho de la desigualdad social y económica ${ }^{27}$. El argumento u objeción de la explotación, o el que se basa en la desigualdad social y económica, corresponde con el que SANDEL llama argumento de la justicia y yo he llamado argumento de la desigualdad. El argumento de la mercantilización, o el que María CASADO relaciona con la justicia y la solidaridad, corresponde con el de la corrupción o degradación.

Por supuesto, los nombres no son lo más importante, aunque un nombre adecuado siempre ayuda. Por eso, cabe apuntar que: i) el nombre de «mercantilización» no me parece el más apropiado en este caso, precisamente porque de lo que se trata es de argumentar a favor o en contra de la propia mercantilización, e incurriríamos, por tanto, en una petición de principio, siquiera sea nominal y con la amenaza de convertirse en sustancial («la mercantilización es mala porque mercantiliza los órganos humanos»); ii) el nombre de «justicia» que usa SANDEL me parece demasiado genérico, puesto que valdría para cualquier argumento relevante en esta materia, también para los que él asocia con la degradación de lo valioso, que, si son válidos, también permitirían calificar como «injusto» el comercio de órganos, y iii) si prefiero «desigualdad» a «explotación» es porque, como se verá, tengo interés en subrayar la desigualdad

25 Buisan, García Manrique, Mautone y Navarro, 2011. Debo aclarar que con «daño» me refiero exclusivamente al daño físico, y solo el argumento basado en este daño es el que queda fuera del análisis. Por supuesto, la degradación moral puede considerarse un «daño», y también la explotación. Estos otros posibles daños, no físicos, sí serán tenidos en cuenta.

26 SANDEL, 2013: 114. SANDEL aplica este mismo doble argumento a la hora de cuestionar la mercantilización en otros ámbitos, como el del ejército o el de la maternidad subrogada (SANDEL, 2011: 90 y ss.).

${ }^{27}$ FABRE, 2006: 135; WICKS, 2016: 147; CASADO, 2016: 23. Análogamente, aunque en este caso en relación con la compraventa de sangre, Ángel PuYOL enuncia como las dos objeciones principales la de la corrupción del altruismo y la de la explotación de los pobres (PUYOL, 2019: 50-51). 
(injusta) de la que se aprovecha o puede generar el comercio de órganos, desde luego vinculada con una posible explotación, aunque quizá no necesariamente.

Brevemente, doy cuenta de otras clasificaciones, para cotejarlas con la dual que propongo de acuerdo con SANDEL, FABRE, Wicks o CASADO. Janet RADClifFe RICHARDS analiza los siguientes argumentos contra el mercado de órganos: daño, menoscabo del altruismo, falta de consentimiento, coacción, explotación y corrupción ${ }^{28}$. $\mathrm{El}$ argumento del daño ya lo hemos descartado. Los argumentos de la falta de consentimiento y de la coacción son variantes del argumento de la desigualdad. El argumento de la explotación puede considerarse o bien una variante del argumento de la desigualdad o bien una del argumento de la degradación, como luego trataré de justificar. El argumento del menoscabo del altruismo que cabe esperar si se mercantilizan los órganos humanos suele analizarse como un argumento independiente de los dos que pretendo manejar aquí. Por cierto que este argumento tiene el mérito de haber sido un elemento central del análisis de las transfusiones de sangre que publicó Richard TiTMUSS en 1970, y que puede considerarse el punto de partida sobre la controversia que nos ocupa, un libro que ya desde el principio suscitó un debate en el que participaron, entre otros, Kenneth ARROW y Peter SINGER, y que se ha prolongado hasta nuestros días ${ }^{29}$. De todas formas, a mi juicio el argumento del altruismo ha de vincularse con el de la degradación, o considerarse como una versión del mismo; pues se trata de que el hecho de que pongamos un precio a las partes o productos del cuerpo humano debilita nuestra tendencia al altruismo (en este caso, a donar sangre), pero entiendo que como consecuencia de una distorsión a la hora de dar sentido y valorar lo corporal. Sea porque debilitar el altruismo es de por sí una degradación de lo valioso, sea porque ese debilitamiento es producto de una degradación de lo corporal, entiendo que el argumento del altruismo puede incluirse en el más genérico de la degradación.

Por su parte, Eduardo RIVERA LÓPEZ identifica el argumento kantiano, el paternalista, el de la pendiente resbaladiza, el de la distribución injusta y el de la explotación ${ }^{30}$. Si no me equivoco, el primero de ellos cabe subsumirlo en el de la degradación, y el segundo, el cuarto y el quinto son variantes del argumento de la desigualdad (algo en lo que insistiré en la sección siguiente); el de la pendiente resbaladiza pertenecerá al ámbito del de la degradación o del de la desigualdad según el mal al que nos veamos abocados a resbalar. Stephen WILKINSON también propone una lista de argumentos contrarios a la venta de órganos humanos, que incluye el argumento del daño, el del altruismo, el de la falta de consentimiento, el de la coacción y el de la explotación, a los que añade más adelante el de la instrumentalización y el de la cosificación ${ }^{31}$. A partir de esta lista cabe practicar la misma reducción que hemos llevado a cabo con la de RADCLIFFE RICHARDS, con el añadido de que los dos últimos argumentos (instrumentalización y cosificación) pueden considerarse versiones del argumento de la degradación (o del que Rivera llama argumento kantiano).

28 RADCLIFFE RICHARDS, 1996.

29 Titmuss, 1973 (la 1. a ed. es de 1970); ArRow, 1972; SingER, 1973. Sobre la relevancia del libro de Titmuss y para más indicaciones acerca del debate que suscitó, vid. CuADros AguILERA, 2018: 163 y ss.

30 RIVERA LÓPEZ, 2001: 163-175.

31 WiLKINSON, 2003: 107-132, y WiLKINSON, 2015: 11-13. 


\section{EL ARGUMENTO DE LA DESIGUALDAD: FORMULACIÓN GENERAL}

El argumento de la desigualdad puede formularse así: si se permite la venta de órganos, es de esperar que sean los más pobres quienes estén dispuestos a vender los suyos, apremiados por la necesidad de obtener recursos financieros a los que no pueden acceder por otros medios; en cambio, los ricos (o los no tan pobres o, si se quiere, quienes tienen sus necesidades básicas cubiertas) no venderán sus órganos porque no tendrán necesidad de ello. Sea cual sea el modo en que describamos la situación en que se encuentran los «pobres» por contraste con los «ricos» (incapaces de emitir un consentimiento genuino, coaccionados, explotados), quienes manejan estos argumentos perciben que se trata de una situación injustamente desigual: unos se ven impulsados a vender sus órganos y los otros no.

Conviene precisar de qué tipo de desigualdad estamos hablando, puesto que no toda desigualdad es mala per se. Una vez legalizada la venta de órganos, todos los ciudadanos (ricos o pobres) tienen una nueva y misma posibilidad jurídica de obrar: pueden decidir vender sus órganos o no venderlos. Sin embargo, es de esperar que sean los pobres y no los ricos quienes vendan sus órganos, puesto que su necesidad de dinero es mayor. Esta mayor necesidad, basada en la desigualdad de partida, es la que explica la nueva desigualdad que produce la legalización de la venta de órganos. Se trata, y esto es lo relevante, de una desigualdad en la libertad, que atenta contra el dogma de la justicia: la igual libertad de todos. Puesto que, en efecto, los ricos son más libres de vender sus órganos, en el sentido de que son tan libres de hacerlo como de no hacerlo, puesto que no necesitan hacerlo para satisfacer necesidades perentorias; y los pobres son menos libres en el sentido de que, si no obligados, sí se ven al menos apremiados o inducidos a vender sus órganos con el fin de satisfacer tales necesidades. Es decir, se permite la misma conducta a todos (vender los órganos), pero, en realidad, dada la previa desigualdad, se está promoviendo que sean solo algunos quienes la lleven a cabo y, por tanto, se está promoviendo que sean solo algunos y no todos quienes provean a la comunidad de los órganos que esta requiere para satisfacer las necesidades de los enfermos.

Sin embargo, la explicación del párrafo anterior no parece suficiente, por esta razón: hay decisiones legislativas que amplían el rango de las decisiones que un ciudadano puede tomar (como en este caso) y que (a diferencia de este caso) no juzgamos negativamente desde el punto de vista de la igual libertad, incluso aunque sea de esperar que sean unos ciudadanos en mayor medida que otros los que tomen esa decisión que ahora es posible y antes no. Imaginemos el caso análogo de la aprobación de una norma que permite alquilar por separado habitaciones de una vivienda previamente arrendada. Seguramente, los arrendatarios más ricos no ejercerán su derecho y serán los más pobres quienes lo hagan, si tienen una habitación disponible. Otro ejemplo, quizá más alejado pero entiendo que también análogo, sería el de una norma que pone en marcha un servicio o bien público gratuito o a bajo precio: un autobús urbano, una piscina, un parque. Seguramente quienes dispongan de vehículo, piscina o jardín propios no disfrutarán de su nuevo derecho tanto como quienes no dispongan de alguna de esas cosas. 
En todos estos casos diríamos que se ha ampliado el ámbito de la libertad, y que se ha ampliado igualmente, porque ahora todos podemos hacer algo que antes no podíamos, por mucho que sean unos más que otros quienes ejerzan esta faceta nueva de su libertad. Por tanto, todavía hay que explicar por qué no vemos así las cosas en el caso de la liberalización de la venta de órganos. De hecho, es la libertad de los menos favorecidos la que parece que aumenta en mayor medida, puesto que serán ellos los más interesados en ese nuevo ámbito de acción. Por eso, algo en lo que insisten reiteradamente los partidarios de la legalización es en que son los pobres quienes más se beneficiarían de ella y que, en consecuencia, resulta paradójico (o directamente contradictorio) prohibir la venta de órganos en su nombre, puesto que al daño que supone su pobreza se añade el daño derivado de prohibir una posible solución para ella ${ }^{32}$. Por supuesto, para desvirtuar esta alegación no basta con acusar de poco compasivos o de muy cínicos a quienes la formulan, ni tampoco con proponer soluciones alternativas a la pobreza. No basta, porque aquí no se trata de resolver la cuestión de cuál sea la mejor solución para el problema de la pobreza ni, por tanto, podemos acusar a nadie de proponer la venta de órganos para remediarla. En cambio, lo que tenemos que hacer es dar una explicación de por qué en el caso de la venta de órganos no nos parece bien que se amplíe el rango de opciones disponibles para una persona y sin embargo en otros casos sí. Si pudiéramos recurrir al argumento del daño físico, tendríamos una explicación muy plausible al alcance de la mano; pero hemos asumido como premisa que la donación de órganos no conlleva daños o riesgos físicos significativos para el donante, luego ese argumento no está disponible. Solo queda afirmar y justificar que hay algo intrinsecamente negativo o perjudicial en la venta de órganos, de manera que la convierte en una mala opción, sean cuales sean las circunstancias; pero no parece que esta afirmación, ni mucho menos su justificación, vayamos a encontrarla en ninguna de las versiones del argumento de la desigualdad, como veremos a continuación con mayor detalle.

Antes de pasar al examen de sus distintas versiones, no está de más apuntar que el argumento de la desigualdad depende del contexto, es decir, no vale (o no vale igual) en cualquier circunstancia, si es que vale en alguna. Puede valer (o valer más) cuando una parte de los ciudadanos se encuentra en una situación de pobreza extrema, aquella en la cual son incapaces de satisfacer sus necesidades más básicas. En cambio, el argumento se debilita si ningún ciudadano está en una situación como esa, sea porque exista un mínimo vital garantizado para todos o sea porque los recursos de la comunidad son abundantes y están suficientemente bien distribuidos ${ }^{33}$. Por supuesto, siempre que exista algún nivel de desigualdad en el disfrute de recursos, el argumento puede seguir siendo invocado, pero habrá que convenir en que su fuerza es inversamente proporcional al nivel de igualdad económica.

Conviene recordar también que el argumento de la desigualdad, si partimos del modelo de mercado de ERIN y HARRIS, vale solo para la obtención de órganos, pero no

32 RAdCLIFFe RichardS, 1996: 381; Wilkinson, 2003: 131; WiCKS, 2016: 149. Se trata de una paradoja también reconocida por quienes se muestran contrarios a la mercantilización de lo corporal (RADIN, 1996: 51).

33 FABRE, 2006: 145; DE LORA, 2011: 1019. Cuestión aparte es la de si en estas condiciones de universal bienestar tendría sentido plantear la venta de órganos, porque nadie estaría dispuesto a vender los suyos (RIVERA LÓPEZ, 2001: 179). 
para su distribución, que, en este modelo, no es desigual en ningún sentido que pueda ser calificado como injusto, sino que sigue pautas en principio no discutidas de justicia sanitaria. En el reparto de órganos que supone este modelo, la capacidad económica de quien necesita un órgano no es relevante. En verdad, así se desvirtúa la más fuerte objeción contra la venta de órganos basada en la desigualdad que puede generar. Sin embargo, que la obtención de órganos se realice en condiciones de injusta desigualdad es suficiente para sostener que el argumento abona la prohibición de la venta.

\section{CONSENTIMIENTO VICIADO, COACCIÓN Y EXPLOTACIÓN}

La pregunta que debemos hacernos es, pues, la siguiente: ¿es injusta la desigualdad que genera la legalización de la venta de órganos? Recordemos que esa desigualdad consiste en que los pobres se verán impulsados a vender sus órganos en mayor medida en que lo serán los ricos y en que, por tanto, serán los pobres (de forma exclusiva o por lo menos mayoritaria) quienes provean de órganos a toda la comunidad. Recordemos también que, en principio, nos enfrentamos a una desigualdad en la libertad, puesto que podemos pensar que los ricos serán más libres de vender sus órganos y los pobres menos, puesto que estarán presionados a hacerlo por su mala situación. Para responder a esta pregunta, me fijaré en tres posibles formas de esta desigualdad: la que deriva de los intercambios mercantiles, la que deriva de un precio injusto y la que deriva de la naturaleza intrínseca de lo vendido. A cada una de ellas dedicaré una sección. Como este creo que no es el modo habitual de abordar la cuestión, haré antes referencia a otro modo que sí lo es, el de vincular la desigualdad con la falta de consentimiento, con la coacción y con la explotación, simplemente para hacer ver cuáles son los conceptos en juego y para mostrar que pueden ser abordados a través del análisis que aquí propongo.

La venta de órganos podría estar afectada, en primer lugar, por un consentimiento viciado, o incluso ausente. Vamos a dejar de lado todo lo relacionado con lo que se llama el «consentimiento informado», porque vamos a suponer que la regulación de un modelo de mercado como el que hemos tomado como referencia (el de ERIN y HARRIS) incluirá las cláusulas necesarias al respecto, de manera que todo posible vendedor haya sido correctamente informado del sentido y consecuencias de su decisión de vender un órgano. Esto significa que el vicio o la falta de consentimiento no derivará de la falta de información, sino acaso de la mala situación económica del vendedor. Así, por ejemplo, Michael SANDEL afirma que, cuando hay una desigualdad económica entre las partes, los intercambios mercantiles no pueden considerarse plenamente libres (esto es, consentidos), puesto que unos se ven forzados a participar en ellos y otros no tanto ${ }^{34}$. En realidad, esto es lo mismo que decir (y SANDEL lo dice) que los pobres están siendo coaccionados, puesto que se les induce o fuerza a vender sus órganos para paliar su mala situación económica, esa en la que no pueden satisfacer sus necesidades básicas si no es vendiendo sus órganos. Por tanto, entiendo que el argumento del consentimiento viciado es el mismo que el de la coacción. Ahora bien, el defecto del consentimiento, o la coacción que lo provoca, podrían derivar del mero hecho del intercambio mercantil

34 SANDEL, 2013: 115. 
en condiciones de desigualdad, como parece sugerir SANDEL, pero también podrían hacerlo de la injusticia del precio o de la naturaleza de lo intercambiado, y entiendo que esto justifica una evaluación separada de cada una de estas posibles causas del daño moral.

En cuanto a la explotación, hay al menos dos posibles interpretaciones del concepto que son relevantes aquí. En primer lugar, cabe pensar que quien vende un órgano está siendo explotado por quien lo compra (en primera instancia) o por quien lo recibe (en última instancia), en el kantiano sentido de que está siendo considerado como un medio y no como un fin en sí mismo o, de manera más amplia, en el sentido de que se produce un aprovechamiento ilegítimo de una persona por parte de otra ${ }^{35}$. Esta primera interpretación de la explotación podemos dejarla aquí de lado porque o bien tiene que ver con el que he llamado el argumento de la degradación (y atisba aquí la sospecha de que ambos argumentos, el de la desigualdad y el de la degradación, no pueden desligarse el uno del otro, pero tendré que dejar esto de lado por el momento), o bien confluye con la segunda interpretación, cuando el aprovechamiento ilegítimo se produce como consecuencia de una «disparidad de valor» en un intercambio ${ }^{36}$.

En segundo lugar, y seguramente como una instancia concreta de la anterior, la explotación parece consistir en la existencia de un resultado desigual en un intercambio mercantil, es decir, en el hecho de que una parte se ve más favorecida que la otra. En el caso típico del trabajo asalariado, tal como es analizado por MARX, la explotación radica en que hay una diferencia (la plusvalía) entre lo que el empresario paga al trabajador (el salario, o precio de su trabajo, o su valor de mercado) y lo que el empresario obtiene del trabajador (el valor de mercado del producto de su trabajo) ${ }^{37}$. En el caso de la venta de órganos, el análisis sería equivalente: el órgano vale más que el precio que se paga por él. Si esto es así, entonces hay explotación. Aquí no ha de importar que el comprador del órgano (por ejemplo, el National Health Service o institución equivalente) y su destinatario final (a quien se trasplanta el órgano) sean distintos, como en el modelo de ERIN y HARRIS. Esto sería relevante al efecto de determinar quién es el explotador (si el NHS, el destinatario final del órgano, o los dos), pero no al efecto de determinar si hay explotación o no, algo que dependerá solo de que el precio pagado por el órgano sea menor que su valor.

Claro está que aquí nos enfrentamos con el problema de que, a diferencia del trabajo y de su producto, que tienen valores de mercado más o menos identificables, en el caso de la venta de órganos podemos identificar el precio pagado por el órgano, pero no es tan fácil identificar el otro «precio» con el que habría que compararlo, puesto que el comprador del órgano no lo venderá a su vez, ni lo utilizará para ninguna actividad de mercado, sino que lo distribuirá de acuerdo con otro tipo de criterios; ni tampoco el destinatario final del órgano «hará negocio» con él, más allá de salvar su vida o de mejorar su salud. Aun así, entiendo que sería posible determinar un «precio» con el que comparar el obtenido por la venta del órgano a fin de establecer si hay o no explotación: un precio que podría tener en cuenta la vida que se salva,

\footnotetext{
35 HaRris, 1998: 168 y ss.; FABRE, 2006: 142.

36 HARRIS, 1998: 176.

37 MARX, 1976: I, 193 y ss.
} 
o la mejora de la salud, o el potencial lucro emergente del sujeto beneficiado, o el ahorro de costes sanitarios que representa un trasplante respecto de otras terapias alternativas.

Será este segundo y más restringido sentido de la explotación el que me ocupe aquí (insisto: no porque el primero y más genérico no sea relevante, sino porque parece vinculado más bien con el argumento de la corrupción, si es que no se concreta en este segundo), y de nuevo entiendo que, como en el caso de la falta de consentimiento o presencia de coacción, para examinar la concurrencia de explotación en la venta de órganos convendrá diferenciar entre la que derivaría del intercambio como tal, la que derivaría del precio o la que derivaría de la naturaleza de lo vendido.

\section{LA DESIGUALDAD DE LOS INTERCAMBIOS MERCANTILES}

La fuerza del argumento de la desigualdad puede residir en que hay intercambios injustamente desiguales, porque se producen digamos entre una parte débil (por su mala situación económica) y una parte fuerte (por su buena situación económica), y en estos casos la parte débil o bien no está en condiciones de prestar un consentimiento válido porque está siendo coaccionada (luego no actúa de manera autónoma), o bien es explotada por la parte fuerte. Ahora bien, si el intercambio es injustamente desigual debido a que existe ese desequilibrio entre las partes, entonces el argumento vale para cualquier intercambio que se produzca entre ellas, esto es, se trata de un argumento formulado en general contra los intercambios entre sujetos desiguales por razón de su distinta capacidad o situación económica, es decir, los intercambios que son típicos de una sociedad al menos parcialmente mercantil, en la que buena parte de los bienes y de los servicios se intercambian en esas condiciones.

Por eso, del mismo modo que se argumenta por esta vía contra la venta de órganos, cabría argumentar, por ejemplo, contra la venta de ciertos tipos de trabajo (o incluso contra el trabajo asalariado en general). Supongamos que una persona $\mathrm{X}$ en mala situación económica acepta un puesto de cajero de supermercado, y supongamos que esa persona no hubiera aceptado ese puesto de trabajo si no fuera por esa su mala situación económica, que le impide satisfacer sus necesidades básicas si no es a través del salario que percibirá. Supongamos también que no tiene alternativas laborales mejores, sino acaso equivalentes (otros puestos de trabajo que podamos valorar del mismo modo que el de cajero de supermercado, por su carácter subalterno, mecánico, alienante, o como se quiera calificar).

En un caso como este, cabría afirmar, simultánea o alternativamente: 1) que el consentimiento de $\mathrm{X}$ no es válido, o es débil, porque $\mathrm{X}$ no aceptaría un trabajo como ese si no fuera por su mala situación económica; 2) que X está siendo coaccionado, esto es, obligado a aceptar ese trabajo, porque, si no lo hiciera, no podría satisfacer sus necesidades básicas, y 3) que $\mathrm{X}$ está siendo explotado, puesto que, a cambio de su trabajo, recibe una compensación monetaria por definición de menor valor. Todo esto podría discutirse; pero lo que importa ahora es darse cuenta de que la discusión no giraría particularmente en torno a la venta de órganos, sino de cualesquiera otros bienes o servicios en condiciones de desigualdad económica previa. 
En consecuencia, así concebido, entiendo que el argumento de la desigualdad prueba demasiado: en realidad, es un argumento contra el mercado en general, bajo condiciones de desigualdad económica. Esto, por supuesto, no convierte en inválido el argumento, pero sí en trivial: si resulta que cualquier intercambio mercantil en condiciones de desigualdad es injusto, entonces también es injusta la venta de órganos en esas mismas condiciones, pero esta conclusión sería un corolario evidente y ya no problemático. Sin embargo, quienes manejan este argumento suelen dar por supuesta la existencia de una sociedad con mercado, esto es, la posibilidad de que la producción y distribución de bienes y servicios se someta a un régimen mercantil; y lo que pretenden es justificar que la obtención y distribución de los órganos (pero no necesariamente de cualquier otra cosa) debe quedar fuera del mercado. Si esto es así, entonces el argumento prueba demasiado porque nos obliga a renunciar a una de nuestras premisas (la existencia de lo mercantil) y nos aboca a una implausible «satanización indiscriminada del mercado» ${ }^{38}$. $\mathrm{O}$, dicho de otro modo, el argumento no convencerá a quienes sean partidarios del mercado, y no aportará nada nuevo a quienes no lo sean, puesto que no será más que una versión particular de un argumento más general que ellos ya han dado por bueno.

Desde luego, gran parte de la discusión que nos ocupa gira en torno al tipo de bienes o servicios que son adecuados para ser comprados y vendidos en el mercado, lo cual supone, repito, que unos deben (o pueden) serlo, y otros no ${ }^{39}$; pero cuando nos ponemos en esta tesitura, la cuestión ya no es la desigualdad del intercambio como tal, sino que esa desigualdad afecte al particular tipo de bien que son los órganos humanos. Y esto nos lleva al otro argumento, el de la degradación, corrupción o indignidad, que requiere examinar cuál sea la naturaleza específica de los órganos humanos y determinar si esa naturaleza los hace específicamente ineptos para constituirse en objetos de tráfico mercantil.

Por otra parte, los partidarios de la venta de órganos pueden (y suelen) razonar así ${ }^{40}$ : no es la posibilidad de vender los órganos la que genera coacción o explotación, sino la previa situación de pobreza extrema, de manera que, ya antes de la legalización de la venta de órganos, la persona X está siendo coaccionada y/o explotada, o sus decisiones mal pueden predicarse autónomas, puesto que: o $\mathrm{X}$ acepta opciones vitales poco valiosas (trabajar como cajero en un supermercado, por seguir con el ejemplo de antes) o no podrá satisfacer sus necesidades básicas. Que se legalice la venta de órganos no puede ser, pues, la causa de la coacción o explotación, ni puede ser condenada porque genere desigualdad, puesto que la desigualdad es previa y la coacción o explotación ya existen. En todo caso, la nueva posibilidad de vender los órganos con el fin de satisfacer necesidades básicas amplía el rango de la opciones X (que ahora podrá optar entre trabajar en el súper o vender un riñón). Desde luego, cabría aducir que lo que exige la autonomía es que $\mathrm{X}$ disponga de un rango de opciones valiosas ${ }^{41}$, y ni la una ni la otra lo son; pero esto no constituye un argumento contra la venta de órganos

38 GARZÓN VALDÉS, 1994: 164.

39 Algunas instancias significativas de esa discusión se encuentran en WALZER, 1983; ANDERSON, 1993; RADIN, 1996; SATZ, 2010; SANDEL, 2013.

40 RADCLIFFE RiCHARDS, 1996: 380 y 391; WICKS, 2016: 149.

41 RAZ, 1986: 372-373; NINO, 1989: 204-205; o SEN, 1993: 34, y 1997: 136. 
en particular, puesto que no cuestiona el hecho de que, desde el punto de vista de la autonomía, siempre será mejor elegir entre dos males de distinta naturaleza que simplemente estar abocado a uno de ellos. Por eso, como veíamos, se insiste en que negar (a los pobres) la posibilidad de vender sus órganos para solventar sus carencias constituye un mal añadido a su pobreza, y es difícil cuestionar esta afirmación si no se entra a valorar la naturaleza específica de esa peculiar venta.

Un caso análogo, que quizá nos permite comprender mejor de qué se trata aquí, es el del trabajo infantil. Hay quienes critican la expansión del trabajo infantil en ciertos países, porque supone coacción y explotación de los niños. Sin embargo, sus partidarios sostienen que esos niños están mejor cuando pueden trabajar que cuando no pueden, dado que, si no pueden, no podrán salir de la miseria por otros medios. En tanto que no dispongan de esos otros medios, la posibilidad de trabajar no lesiona (más) su autonomía o, en general, su bienestar, sino todo lo contrario. O, por decirlo crudamente, entre morir de hambre sin trabajar y sobrevivir trabajando, la segunda posibilidad es mejor (aunque uno sea un niño). También en este caso no queda más remedio que reflexionar acerca del mal específico que supone el trabajo infantil si se quieren encontrar argumentos para combatirlo, pues no bastarán invocaciones más genéricas. Que la naturaleza particularmente odiosa del trabajo infantil sea más evidente que la naturaleza (acaso) igualmente odiosa de la venta de órganos, lo único que pone de relieve es que nuestras convicciones acerca del sentido de la infancia son más claras o más sólidas que aquellas que tenemos acerca del sentido de lo corporal.

\section{LA DESIGUALDAD DERIVADA DE UN PRECIO INJUSTO}

El argumento de la desigualdad admite una segunda versión, de acuerdo con la cual el problema de la venta de órganos no radica en el hecho del intercambio mercantil en sí, sino en uno de sus elementos: el precio. En este caso, lo que se aduce es que la venta de órganos sería injustamente desigual porque el precio sería demasiado bajo y, por tanto, generaría explotación del vendedor por parte del comprador, puesto que el primero obtendría más de lo que obtendría el segundo: el órgano valdría más que el precio que se ha pagado por él. Por supuesto, la validez de esta versión del argumento depende de que, en efecto, el precio sea demasiado bajo. Dos preguntas surgen inmediatamente. La primera: ¿cuándo es bajo el precio de un órgano? Y la segunda: ¿será necesariamente bajo el precio que alcanzarán los órganos en el mercado?

El precio de un órgano será bajo cuando sea menor que el precio «justo». No puedo ocuparme aquí en profundidad de una categoría tan problemática como esta. En todo caso, asumiré que el precio justo de un bien o servicio no es su precio de mercado, entendido como el resultado de la libre confluencia de la oferta y la demanda. Esto, por tres razones: en primer lugar, porque la percepción que tenemos de la idea del «precio justo» es la de un precio con el que comparar el precio de mercado, para poder calificar a este como alto o bajo (cuestión aparte es la de si tiene sentido dicha comparación, al menos en determinados ámbitos del mercado; pero, si no la tuviera, la propia categoría del precio justo perdería su interés). En segundo lugar, porque el precio justo, en tanto que justo, parece tener que basarse en consideraciones de justicia, que requieren ir más 
allá de las dinámicas del mercado (que no dependen de ese tipo de consideraciones) y preguntarse por el valor intrínseco de un bien o servicio y por el esfuerzo que le supone a un sujeto su adquisición. Así, por ejemplo, cuando se dice que el precio de la vivienda es demasiado elevado ( $y$, por tanto, injusto), suele hacerse teniendo en cuenta el carácter de la vivienda como bien de primera necesidad, y la relación entre los ingresos de una persona y la parte de ellos que ha de dedicar a su compra o alquiler, factores estos que, en principio, quedan al margen de la relación entre la oferta y la demanda. En tercer lugar, porque, quizá como consecuencia de lo anterior, hay instancias bien conocidas de precios mínimos o máximos fijados por las autoridades públicas con el fin de evitar que rija el precio de mercado, considerado injusto. El salario mínimo o las tarifas máximas de suministro eléctrico bastan para ejemplificar el fenómeno.

Aun asumiendo que haya tal cosa como un precio justo, no resulta fácil fijarlo para los órganos humanos, quizá precisamente porque no partimos de referencia alguna, o de muy pocas. Un intento es el de BECKER y ELÍAS. En realidad, estos autores no manejan la categoría de «precio justo», sino que se preguntan «cuánto hay que pagar para inducir a un individuo a vender un órgano» ${ }^{42}$; pero, teniendo en cuenta el tipo de respuesta que articulan, podemos dar por bueno que se trata de un intento de fijar un precio justo. En efecto, para responder, agregan tres cantidades, que responden a otras tantas compensaciones monetarias por: i) el riesgo de muerte; ii) el tiempo perdido durante la convalecencia posterior a la extracción, y iii) el riesgo de una reducción de la calidad de vida. Según sus cálculos, el precio de un riñón rondaría los 15.000 dólares y el de un segmento de hígado los $37.000^{43}$.

¿Es justo este precio? ¿O parece demasiado alto o demasiado bajo? Es difícil decirlo. A bote pronto, llama la atención que el precio de un riñón sea equivalente al de, por ejemplo, un vehículo utilitario, porque uno bien podría pensar que el valor del riñón es superior al del vehículo y que, por tanto, se trata de un precio bajo. Desde luego, teniendo en cuenta el nivel de los salarios en Estados Unidos (o incluso en España, para el caso), es difícil pensar que con ese precio se evitara que fueran exclusivamente los pobres quienes se plantearan vender su riñón ${ }^{44}$. Es decir, que quizá se produciría el efecto que tanto temen los adversarios del mercado de órganos: una desigualdad muy acentuada, si resulta que la opción de vender un riñón fuera solo atractiva para los pobres; en este caso, bien podríamos decir que los pobres están siendo explotados.

Claro está que, precisamente por considerar bajo ese precio, podemos pensar que otros precios superiores no serían bajos, sino justos, al menos en algún sentido, y una

42 BECKER y ELÍAS, 2007: 9.

43 BECKER y ELÍAS admiten que su cálculo depende de estimaciones discutibles y que, en función de otras estimaciones, el precio del riñón podría establecerse entre 7.000 y 28.000 dólares, y el del fragmento de hígado entre 18.000 y 69.000 (BECKER y ELÍAS, 2007: 15). Para el caso de los riñones, estas cifras se mantienen similares (entre 5.000 y 25.000 dólares) en una fecha posterior (BECKER y ELÍAS, 2014: 4). Que un riñón llegase a alcanzar un precio de 5,8 millones de dólares en e-Bay, hasta que el gobierno americano ordenó la clausura de la subasta (SATZ, 2010: 192) no deja de ser anecdótico y poco significativo, precisamente porque no existe un mercado legal y regulado de órganos.

44 El salario medio en Estados Unidos, en 2017, fue de 44.564 dólares, según la web thebalancecareers. com. 23.156 euros fue el salario medio en España en 2018, según datos del INE (unos 25.700 dólares al cambio actual). 
buena señal de esa justicia sería que quienes disfrutan de una posición acomodada se plantearan vender un riñón no para cubrir sus necesidades básicas (que ya tendrían satisfechas por otros medios), sino para satisfacer otros planes de vida más caros, inasequibles para ellos con esos medios ordinarios. Podríamos decir que el precio de un órgano sería justo si amplía las oportunidades vitales no ya solo de los pobres, sino de la mayoría de los ciudadanos. Pensemos, por ejemplo, en un precio de 60.000 euros para un riñón, que cuatriplica el estipulado por BECKER y ELÍAs. Es cierto que, desde su punto de vista, quizá sería un precio demasiado alto, teniendo en cuenta que otra variable que consideran a la hora de proponer un mercado de órganos es que el precio del órgano no tenga un impacto muy grande en el coste del trasplante. En efecto, este coste lo estiman en unos 160.000 dólares $^{45}$, con lo que solo aumentaría en poco menos del 10 por 100 si hubiera que pagar el riñón a 15.000 dólares, pero en cerca del 40 por 100 si hubiera que pagarlo a $60.000^{46}$. Aun así, si tomáramos en cuenta también la reducción de costes sanitarios y de otro tipo que supondría la reducción del tiempo de espera de un trasplante (debida al aumento de la oferta de órganos), quizá ese precio sería asumible.

Pues bien, en este caso, el señor X, que gana (supongamos) unos 15.000 euros anuales en el supermercado donde trabaja, tendría la opción de abandonar ese empleo durante cuatro años para dedicarse a otras actividades más valiosas; pero también un funcionario público que tuviera un sueldo de 30.000 euros anuales (bastante por encima del salario medio español) podría optar por pedir una excedencia de dos años para escribir esa novela que lleva pergeñando tanto tiempo, o para dar esa vuelta al mundo con la que tanto ha soñado, o por seguir trabajando y pagar los estudios de su hijo en una universidad extranjera. Parecería que el señor X o ese funcionario público (y con ellos la mayor parte de la población) están ganando libertad, pues se les abren oportunidades vitales valiosas que antes no tenían. ¿Podríamos seguir afirmando que uno u otro, o los dos, están siendo explotados? Lo dudo ${ }^{47}$. Es decir, si podemos concluir que un cierto precio es «justo», entonces el argumento de la desigualdad (o de la explotación) no sería válido ${ }^{48}$. O, como sostiene Cécile FABRE, «no es plausible pensar que ninguna cantidad de dinero puede compensar la pérdida de un riñón, sangre o una córnea» ${ }^{49}$.

Desde luego, habrá quien se oponga a esta última opinión, con el argumento de que ningún precio que se fije para un órgano humano, por alto que sea, puede ser justo, porque el valor de los órganos humanos no se puede pagar con dinero (esto es, los órganos humanos no tienen precio). Esta forma de pensar recuerda por ejemplo la idea de pluralidad de las «esferas de la justicia» de Michael WALZER, la del pluralismo

45 BECKER y ELÍAS, 2007: 9 y 12.

46 En un país como España, ese precio de 60.000 euros para un riñón sería aún más alto, no solo porque los salarios (y seguramente el coste de la vida) son más bajos, sino porque el coste estimado para un trasplante de riñón es sensiblemente más bajo, precisamente unos 60.000 euros, con lo que estaríamos doblando ese coste.

47 Los que no duden todavía pueden preguntarse si habría explotación en el caso de que la venta de un riñón, en vez de con una cantidad única de dinero, se pagara con un ingreso mensual de por vida equivalente al salario mínimo, siendo su percepción compatible con cualesquiera otras.

48 WiLKINSON, 2003: 131-132.

49 FABRE, 2006: 143. 
de lo valorativo de Elizabeth ANDERSON, o la de que hay cosas que el dinero no puede comprar, de Michael SANDEL ${ }^{50}$. Si así se juzga, resulta que el valor de un órgano no puede hacerse equivaler con precio alguno, porque no es «conmensurable» ${ }^{51}$; pero en este caso entramos claramente en otro terreno argumentativo, el que basa la oposición a la venta de órganos en la degradación que pueden sufrir determinados bienes cuando se les pone un precio. Siendo así, el argumento de la desigualdad se diluye en el argumento de la degradación, es decir, no se sostiene por sí mismo.

Quienes, en cambio, sí crean que el precio es relevante a la hora de valorar la justicia o injusticia del comercio de órganos, puesto que cabe la posibilidad de establecer un precio justo, habrán de preguntarse a continuación si un precio tal es posible o si, por el contrario, será inevitablemente bajo y, por tanto, dará lugar a explotación. El temor que late en esta pregunta es el de que haya el suficiente número de personas desesperadas por su mala situación económica como para ofrecer sus órganos a precios demasiado bajos. Sin embargo, en un modelo como el de ERIN y HARRIS, estamos en condiciones de evitar esa posible explotación mediante la fijación pública de los precios, del mismo modo que se fija un salario mínimo o tarifas máximas para suministros básicos. El hecho de que el comprador de los órganos sea único y público, que es uno de los elementos de ese modelo, facilita el establecimiento de un precio único y justo (siempre según la suposición de que un precio justo sea posible) y, por otra parte, no hay nada de inconsistente en que los ciudadanos tengan el derecho de vender sus órganos pero no tengan el derecho de fijar el precio ${ }^{52}$. En cambio, en una propuesta como la de BECKER y ELÍAS, donde el criterio para la fijación del precio es «cómo inducir» a un individuo a vender un órgano, el peligro de que el precio sea demasiado bajo existe; y creo que muchos lectores coincidirán conmigo en que los 15.000 dólares que sugieren confirman ese peligro.

En definitiva, si el problema es el precio, el argumento de la desigualdad contra el comercio de órganos prueba demasiado poco: solo prueba que tal comercio generaría una desigualdad injusta si el precio que alcanzaran los órganos en el mercado fuera demasiado bajo; pero esta consecuencia puede predicarse de muchos otros tipos de comercio, y además tenemos medios para combatirla cuya eficacia ha sido ya probada. Es más: si nuestro principal temor es que los pobres sean explotados porque van a recibir un precio muy bajo a cambio de su órgano (y no por otras razones), diría que la legalización es mejor que el mercado negro porque permite controlar mejor los precios $^{53}$.

\section{LA DESIGUALDAD VINCULADA CON LA NATURALEZA ESPECÍFICA DE LO CORPORAL}

Hay todavía una tercera forma de entender el argumento de la desigualdad, de acuerdo con la cual el problema de la venta de órganos no radica en que sea una venta,

\footnotetext{
50 WALZER, 1983; ANDERSON, 1993; SANDEL, 2013.

51 RADIN, 1996: 8.

52 FABRE, 2006: 150.

53 RIVERA LÓPEZ, 2001: 170.
} 
o en que el precio sea o pueda ser demasiado bajo, sino en que lo sea de órganos. Ahora lo que se alega es que quien vende un órgano no está en condiciones de emitir un consentimiento válido, o que lo vende porque está siendo coaccionado por su situación o por el estímulo económico, o que está siendo explotado por los compradores o los receptores del órgano. Todo ello, no porque se trate de una transacción mercantil o porque el vendedor no obtenga un precio equivalente al valor real de lo que vende, sino porque se trata de partes del cuerpo humano, y que unos pongan su cuerpo a disposición de otros a cambio de un precio genera una injusta desigualdad, una singular forma de explotación, que no debería permitirse.

En esta tercera versión, el argumento de la desigualdad no prueba nada porque su validez depende por entero de un juicio sobre la naturaleza y el valor intrínsecos de lo corporal, que nos haga ver que resulta particularmente inapropiado para el intercambio mercantil porque genera una distorsión de esa naturaleza y ese valor. Si este fuera el caso, entiendo que el problema del comercio de órganos no radicaría tanto en algún tipo de desigualdad, sino en la articulación de relaciones sociales que generan una falta de respeto por nuestros cuerpos (el propio y los ajenos), que nos impiden apreciar su sentido. En consecuencia, es de este sentido del que hay que ocuparse en primer lugar, y solo secundariamente de una posible desigualdad derivada de ignorarlo. En otros términos, esta versión del argumento de la desigualdad parece más bien una versión oculta del argumento de la degradación.

Hasta aquí, mi intención ha sido mostrar que oponerse a un mercado de órganos no es fácil si recurrimos solo a la idea de la desigualdad y a las que podemos vincular con ella (consentimiento viciado, coacción, explotación), y siempre y cuando ese mercado se configure adecuadamente. Sin embargo, Anne PHILliPs ha insistido en que es precisamente la desigualdad, y no cualquier consideración sobre el valor intrínseco de lo corporal, lo que convierte al mercado de órganos en una práctica indeseable. De hecho, a su juicio, cualquier argumento basado en ese supuesto valor intrínseco está condenado a fracasar, puesto que somos seres «encarnados» (embodied) y eso implica que nuestro cuerpo está implicado en cualquier actividad que llevemos a cabo. Por eso:

Es difícil establecer distinciones claras entre actividades que involucran el cuerpo y las que «solo» involucran la mente; difícil, por tanto, justificar la prohibición del pago por servicios explícitamente corporales mientras lo aprobamos para aquellos en los que el cuerpo es más incidental [...]. No tendría sentido imponer un embargo sobre cualesquiera intercambios monetarios que involucren «el cuerpo», porque hacer eso supondría un embargo sobre cualquier tipo de contrato laboral [...]. No es tan fácil señalar qué es lo que hace al cuerpo tan especial, o provee la piedra angular para separar el comercio legítimo del ilegítimo ${ }^{54}$.

Siendo así, ¿cuál es el problema con la venta de órganos y con otras actividades que solemos vincular especialmente con lo corporal, como la prostitución o la maternidad subrogada? Es la desigualdad, conviene la autora, pero una desigualdad peculiar, en el sentido de que es necesaria, y no contingente, para la existencia de un mercado de órganos, a diferencia de otros mercados. Es decir, otros mercados son criticados porque se desenvuelven en las actuales condiciones de desigualdad, pero podemos

54 PhILliPs, 2011: 733. 
suponer que seguirían existiendo incluso en condiciones ideales de igualdad, porque expresarían la opción de cada uno por la especialización en la prestación de uno u otro tipo de servicio a los demás, una especialización del trabajo que requiere la existencia de un mecanismo de intercambio como el mercado. En cambio, en esa situación ideal de igualdad, nadie se especializaría en la venta de su propio cuerpo, dado que «todos tenemos un cuerpo». Por tanto:

En un mundo imaginario de igualdad social, económica y de género, ¿por qué algunos optarían, entre todas las actividades posibles, por especializarse en la venta de riñones? Es difícil concebir lo que, en esas circunstancias, podría animar a alguien a venderlos [...]. Cuesta ver por qué surgiría un mercado de órganos humanos o servicios corporales, si no es porque hay desigualdad ${ }^{55}$.

El argumento de la profesora de la LSE parece ser, pues, el siguiente: si un mercado de órganos no surgiría espontáneamente en condiciones de igualdad, entonces resulta que ese mercado, a diferencia de otros, tiene una vinculación necesaria con la desigualdad, lo cual lo convierte en cuestionable. La validez de este argumento ha de residir en que sea cierto que nadie, en esas condiciones de igualdad, estaría dispuesto a vender sus órganos. Ahora bien, para justificar esta afirmación no podemos apoyarnos en consideraciones empíricas (puesto que no hemos conocido una situación tal de igualdad), sino en consideraciones sobre nuestra humana forma de ser. La única que aduce PHILLIPS es que «todos tenemos un cuerpo», con lo que sería extraño que empleáramos nuestra libertad en «especializarnos» en una tarea (la de vender órganos) que nada tiene de especial, que en verdad no nos especializa, a diferencia del diseño de páginas web, la carpintería, el masaje o el atletismo, actividades todas ellas que involucran el cuerpo en distintas medidas, pero que van siempre más allá de la mera puesta a disposición de nuestro cuerpo al servicio de otros.

Esta forma de razonar no me parece convincente, precisamente porque no se explica a satisfacción el porqué de esta renuencia a la venta de órganos. Por el contrario, cabría imaginar al menos dos motivos que explicaran por qué alguien querría vender sus órganos. Uno sería que aquello en lo que uno quiere especializarse en ejercicio de su libertad de elección no tuviera valor alguno de mercado (no tuviera interés para los demás) y, para mantener esa especialización y poder seguir disfrutando de ella, buscara otro medio para satisfacer sus necesidades. Otro sería que tuviéramos deseos particularmente caros que requirieran la arrogación de recursos adicionales a los que obtenemos por la ordinaria vía de la especialización, y esto dando por supuesto que todas nuestras necesidades básicas estuvieran satisfechas por esta vía. Ante la posibilidad de casos como estos, ¿por qué un mercado de órganos nos impulsa a concebirnos como «individuos separados» (beings apart) en vez de vinculados? ¿Por qué el efecto de un mercado de órganos es el de «negar nuestra igualdad moral»? ${ }^{56}$. A mi juicio, la respuesta no puede residir más que en la especial naturaleza de lo corporal, esa que PHILlIPS ha empezado por rechazar. Sin tenerla en cuenta, es difícil comprender por qué, en condiciones ideales de igualdad, algunos de nosotros no íbamos a estar dispuestos a vender nuestros órganos. Por eso, tampoco en esta versión resulta convincente el argumento de la desigualdad.

55 Ibid., 738.

56 PHILLIPS, 2011: 738 y 739. 


\section{CONCLUSIÓN}

Un mercado de órganos configurado de acuerdo con principios de justicia (comprador único y público, circunscripción al ámbito de un solo estado, precio único y justo, distribución de los órganos según criterios estrictamente sanitarios) tiene a su favor una presunción de legitimidad, basada en el argumento de que contribuye a salvar vidas humanas y a mejorar la salud de muchos enfermos. Para desvirtuar esta presunción, se han formulado argumentos vinculados con la desigualdad social y argumentos vinculados con la degradación del valor de lo corporal. Si mi análisis es correcto, ningún argumento del primer tipo (como los que invocan la falta de consentimiento, la coacción o la explotación) resulta suficiente por sí mismo, porque ninguno de ellos acredita que tales daños a la justicia hayan de producirse necesariamente. Es decir, un mercado de órganos podría diseñarse para evitarlos. Por tanto, quien tenga la intención de justificar su negativa a la comercialización de los órganos humanos deberá buscar no por el lado de la desigualdad que genera, o de la que se aprovecha, sino por el lado de la posible falta de respeto que supone para la naturaleza o sentido de lo humano corporal, y la consiguiente degradación de su valor.

\section{BIBLIOGRAFÍA}

Anderson, E. S., 1993: Value in Ethics and Economics, Cambridge, Mass.: Harvard University Press.

Arrow, K. J., 1972: «Gifts and Exchanges», Philosophy and Public Affairs, 1, 343-362.

AtienZA, M., 2010: Bioética, Derecho y argumentación, Lima y Bogotá: Temis.

BeCKeR, G., y ElíAs, J. J., 2007: «Introducing Incentives in the Market for Live and Cadaveric Organ Donations», Journal of Economic Perspectives, 21, 3-24.

— 2014: «Cash for Kidneys: The Case for a Market for Organs», Wall Street Journal, 18 de enero.

Buisan, L.; García Manrique, R.; Mautone, M., y Navarro, M., 2011: Documento sobre trasplante de órganos de donante vivo, Barcelona: Observatorio de Bioética y Derecho de la Universidad de Barcelona.

CASAdO GONZÁLEZ, M., 2016: «¿Gratuidad o precio? Sobre el cuerpo humano como recurso», en M. CASADO (coord.), De la solidaridad al mercado. El cuerpo bumano y el comercio biotecnológico, México: Fontamara, 15-32 (reeditado en 2017 por Ediciones de la Universidad de Barcelona).

Cuadros Aguilera, P., 2017: «Salus populi, principio de no lucro y deber cívico de donar sangre», Revista de Bioética y Derecho, 40, 115-124.

- 2018: La donación de sangre. Historia y crítica de su regulación, Cizur Menor: Civitas.

De LorA, P., 2011: «Justicia y distribución de recursos. El caso de los trasplantes de órganos y tejidos», en M. Gascón Abellán, M. C. González Carrasco y J. Cantero MarTínez (coords.), Derecho sanitario y bioética. Cuestiones actuales, Valencia: Tirant lo Blanch, 10131029.

— 2012: «El trasplante de órganos y el “caso del tranvía”. ¿Por qué no confiscamos órganos de cadáver?», Jueces para la Democracia, 74, 11-25.

- 2018: «Gestar para otros: una ecografía de las falacias», Dilemata. Revista Internacional de Éticas Aplicadas, 28, 75-86. 
ERIN, C. A., y HARRIS, J., 1994: «A monopsonistic market, or how to buy and sell human organs tissues and cells ethically», en I. ROBINSON (ed.), Life and death under high technology medicine, Manchester: Manchester University Press, 134-153.

- 2002: «An ethically defensible market in organs. A single buyer like the NHS is an answer», British Medical Journal, 325, 114-115.

- 2003: «An ethical market in human organs», Journal of Medical Etbics, 29, 137-138.

Escobar Roca, G., 2018a: «El estatuto constitucional del cuerpo humano, entre libertad y dignidad», en R. GARCía MANRIQUE (coord.), El cuerpo diseminado. Estatuto, uso y disposición de los biomateriales bumanos, Cizur Menor: Civitas, 53-79.

- 2018b: Nuevos derechos y garantías de los derechos, Madrid: Marcial Pons.

FABRE, C., 2006: Whose Body is it Anyway? Justice and the Integrity of the Body, Oxford: Clarendon.

García MAnRique, R., 2016: «¿Es mío mi cuerpo? Sobre la propiedad privada del cuerpo humano», en M. CASADO (coord.), De la solidaridad al mercado. El cuerpo bumano y el comercio biotecnológico, México: Fontamara, 103-132 (reeditado en 2017 por Ediciones de la Universidad de Barcelona).

- 2018a: «Sobre la propiedad privada de los biomateriales humanos», en R. GARCÍA MANRIQUE (coord.), El cuerpo diseminado. Estatuto, uso y disposición de los biomateriales humanos, Cizur Menor: Civitas, 119-151.

- 2018b: «La dimensión corporal de la ciudadanía», en R. GARCía MANRIQUE (coord.), El cuerpo diseminado. Estatuto, uso y disposición de los biomateriales bumanos, Cizur Menor: Civitas, 13-32.

GARZÓN VALDÉS, E., 1994: «Algunas consideraciones éticas sobre el trasplante de órganos», Isonomía, 1, 151-189.

HARRIS, J., 1998: Supermán y la mujer maravillosa. Las dimensiones éticas de la biotecnología bumana, Madrid: Tecnos.

MAHDAVI-MAZDEH, M., 2012: «The Iranian model of living renal transplantation», Kidney International, 82, 627-634.

MARX, K., 1976: El Capital: crítica de la economía política, Barcelona: Grijalbo.

MATESANZ, R., 2018: «Irán: un mercado regulado de órganos», 20 minutos, 14 de marzo.

MÉNDEZ BAiges, V., 2018: «En manos del legislador: acerca del estatuto jurídico de los materiales biológicos de origen humano», en R. GARCÍA MANRIQUE (coord.), El cuerpo diseminado. Estatuto, uso y disposición de los biomateriales bumanos, Cizur Menor: Civitas, 33-51.

Moya Guillem, C., 2015: «¿Límites justificados a la autonomía individual? A propósito de la prohibición penal del comercio de órganos humanos», en A. Doval País (dir.) y C. MoYA GuILlEM (coord.), Nuevos límites penales para la autonomía individual y la intimidad, Cizur Menor: Aranzadi, 45-66.

NinO, C. S., 1989: Ética y derechos bumanos, Barcelona: Ariel.

Pascual Medrano, A., 2018: «La interminable configuración del derecho a la integridad física», Revista Española de Derecho Constitucional, 114, 47-72.

PhILlIPS, A., 2011: «It's My Body and I'll Do What I Like With It: Bodies as Objects and Property», Political Theory, 39: 724-748.

Pons Rafols, X., 2016: «Nuevos desarrollos en la lucha internacional contra el tráfico de órganos humanos: el Convenio de Santiago de Compostela», Revista Electrónica de Estudios Internacionales, 31, 1-36.

Puyol, Á., 2019: «Ética, solidaridad y donación de sangre. Cuatro perspectivas a debate», Revista de Bioética y Derecho, 45, 43-58. 
RADCLIFFE RiCHARDS, J., 1996: «Nephrarious goings on», The Journal of Medicine and Philosophy, 21, 375-416.

- 2003: «Commentary. An ethical markets in human organs», Journal of Medical Ethics, 29, 139-140.

Radin, M., 1996: Contested Commodities, Cambridge, Mass.: Harvard University Press.

RAz, J., 1986: The Morality of Freedom, Oxford: Clarendon Press.

Rivera López, E., 2001: Ética y trasplantes de órganos, México, D. F.: UNAM y Fondo de Cultura Económica.

Rothman, S. M., y Rothman, D. J., 2006: «The Hidden Cost of Organ Sale», American Journal of Transplantation, 6, 1524-1528.

SANDEL, M., 2011: Justicia. ¿Hacemos lo que debemos?, Barcelona: Debate.

- 2013: Lo que el dinero no puede comprar. Los límites morales del mercado, Barcelona: Debate.

SATZ, D., 2010: Why Some Things Should Not Be for Sale? The Moral Limits of Markets, Oxford: Oxford University Press.

SAVUlESCU, J., 2003: «Is the sale of body parts wrong?», Journal of Medical Ethics, 29, 138-139.

Sen, A., 1993: «Capability and Well-being», en A. Sen y M. Nussbaum (eds.), The Quality of Life, Oxford: Oxford University Press.

- 1997: Bienestar, justicia y mercado, Barcelona: Paidós.

Singer, P., 1973: «Altruism and Commerce: A Defense of Titmuss against Arrow», Philosophy and Public Affairs, 2, 312-320.

Sunstein, C. R., 2019: On Freedom, Princeton y Oxford: Princeton University Press.

Titmuss, R. M., 1973 [1970]: The Gift Relationship. From Human Blood to Social Policy, Harmondsworth: Penguin.

Walzer, M., 1983: Spheres of Justice. A Defence of Pluralism E Equality, Oxford: Blackwell.

Wicks, E., 2016: The State and the Body. Legal Regulation of Bodily Autonomy, Oxford: Hart.

WiLKINSON, S., 2003: Bodies for sale. Ethics and Exploitation in the Human Body Trade, London: Routledge.

- 2015: «The Sale of Human Organs», Stanford Encyclopedia of Philosophy (online). 